\title{
Progressive symmetric vertical macular wide angioid streak-like lacquer crack
}

\author{
This article was published in the following Dove Press journal: \\ International Medical Case Reports Journal \\ 19 April 2016 \\ Number of times this article has been viewed
}

\author{
Ahmad M Mansour ${ }^{1,2}$ \\ 'Department of Ophthalmology, \\ American University of Beirut, \\ ${ }^{2}$ Department of Ophthalmology, Rafic \\ Hariri University Hospital, Beirut, \\ Lebanon
}

Purpose: We report an unusual case of bilateral vertical lacquer crack with no history of ocular trauma and with progressive marked enlargement and consequent visual loss.

Methods: Three-year follow-up was completed using best-corrected visual acuity, serial fundus photographs, intravenous fluorescein angiography, and optical coherence tomography.

Results: We report the occurrence of lacquer crack in a 43-year-old woman with no history of trauma except for laser in situ keratomileusis surgery for mild myopia (as reported by the patient) in the past 5 years and habitual ocular rubbing. Lacquer crack started in the right eye and became evident 1 year later in the left eye. Serial photography after repeated intravitreal injections of ranibizumab for subfoveal choroidal new vessel showed the lacquer crack widened gradually in both eyes. Axial length measurement revealed the presence of high myopia. Bestcorrected visual acuity dropped to $20 / 200$ bilaterally.

Conclusion: We hypothesize that a thin Bruch's membrane in high myopia is prone for small rupture initially either spontaneously or following laser in situ keratomileusis and subsequent widening of the rupture by oculopression and intravitreal injections from rise in intraocular pressure.

Keywords: angioid streak, Bruch's membrane rupture, choroidal rupture, choroidal neovascularization, high myopia, lacquer crack, LASIK

\section{Introduction}

Three diseases that involve Bruch's membrane give somewhat similar fundus appearance in different clinical settings: choroidal rupture (trauma), ${ }^{1-3}$ angioid streaks (pseudoxanthoma elasticum), ${ }^{4,5}$ and lacquer cracks (high myopia). Choroidal rupture is a break in the retinal pigment epithelium, Bruch's membrane, and throughout the choroid following blunt trauma. Clinically, it appears as single (or multiple) white or yellowish crescent-shaped subretinal streak concentric to the optic disc. ${ }^{1,2}$ During a closed globe injury, the eyeball is initially compressed followed by rapid rebound expansion. The sclera's tensile strength resists this compression. The retina is elastic and stretches during such an injury. However, Bruch's membrane lacks elasticity and breaks, taking with it the overlying retinal pigment epithelium and underlying choroid. On the other hand, angioid streaks usually emanate from the disc, tend to be straighter, and are reddish in color. Angioid streaks are associated with several systemic diseases, the most common being pseudoxanthoma elasticum. ${ }^{4-6}$ Bruch's membrane in pseudoxanthoma elasticum is markedly thickened and calcified losing its elasticity and, hence, becomes brittle with dehiscence after minor trauma. ${ }^{5}$ The third disease, lacquer crack, is typically found in high myopia (with a prevalence ranging from $4.3 \%$ to $9.2 \%$ ). ${ }^{7-10}$
Correspondence:Ahmad Mansour Department of Ophthalmology, American University of Beirut, PO Box I I 3-6044, Beirut, Lebanon $\mathrm{Tel}+96$ I I 3377633

Email ammansourmd@gmail.com
International Medical Case Reports Journal 2016:9 95-99

95

(c) (1) (2) $\odot 2016$ Mansour. This work is published and licensed by Dove Medical Press Limited. The full terms of this license are available at https://www.dovepres.com/terms.php cc. hereby accept the Terms. Non-commercial uses of the work are permitted without any further permisision from Dove Medical Press Limited, provided the work is properly attributed. For permission for commercial use of this work, please see paragraphs 4.2 and 5 of our Terms (https://www.dovepress.com/terms.php). 


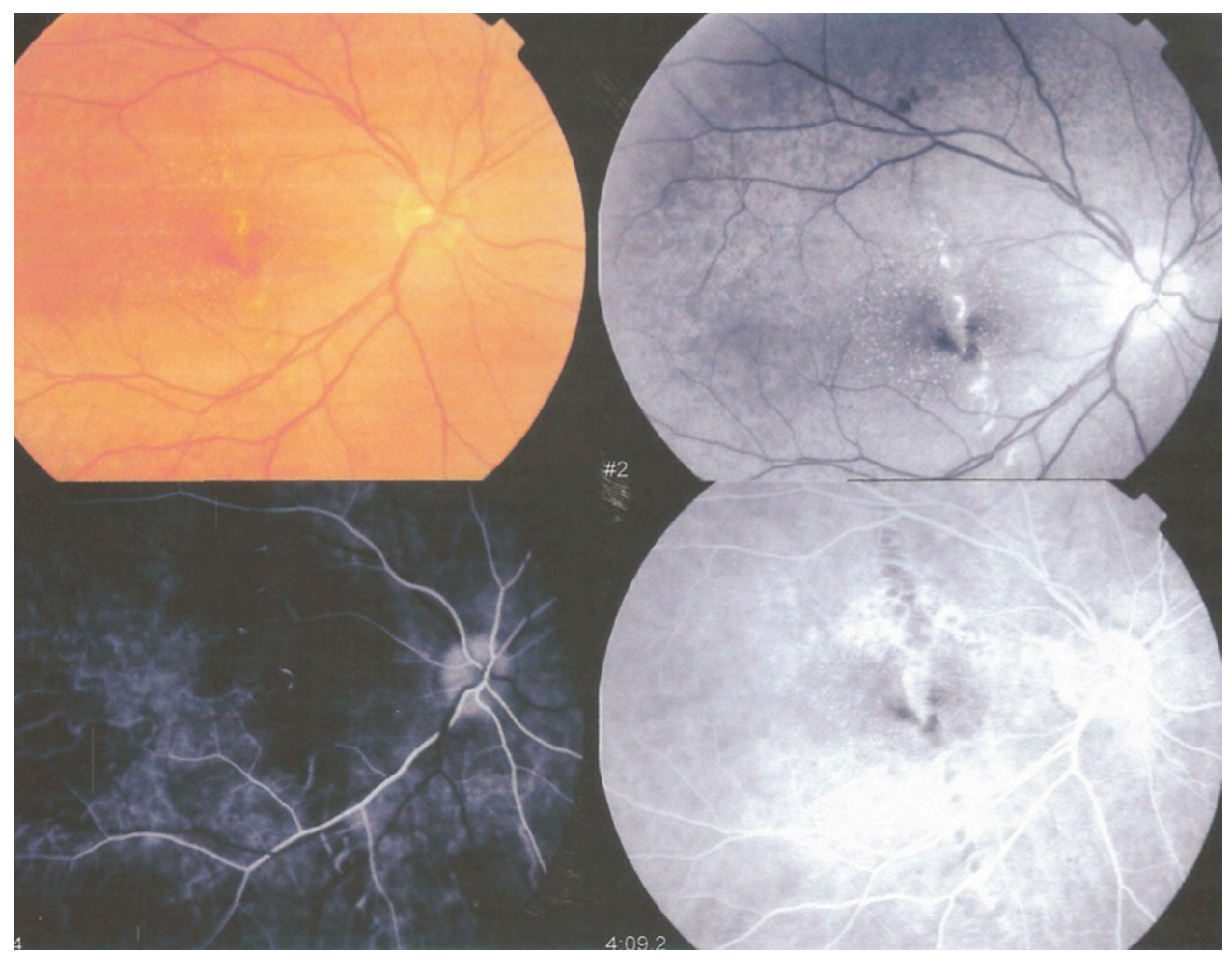

Figure I Initial fundus photographs of the right eye with fluorescein angiography transit show vertical lacquer crack in the fovea (February 2012 ).

Experimentally and histologically, lacquer cracks represent healed and mechanical breaks of the retinal pigment epithelium, Bruch's membrane, and choriocapillaris complex. ${ }^{11} \mathrm{We}$ present a case of progressive sequential bilateral very wide single vertical macular angioid streak-like lacquer crack with no history of blunt trauma and with gradual visual loss after intravitreal injections for choroidal new vessel (CNV) formation.

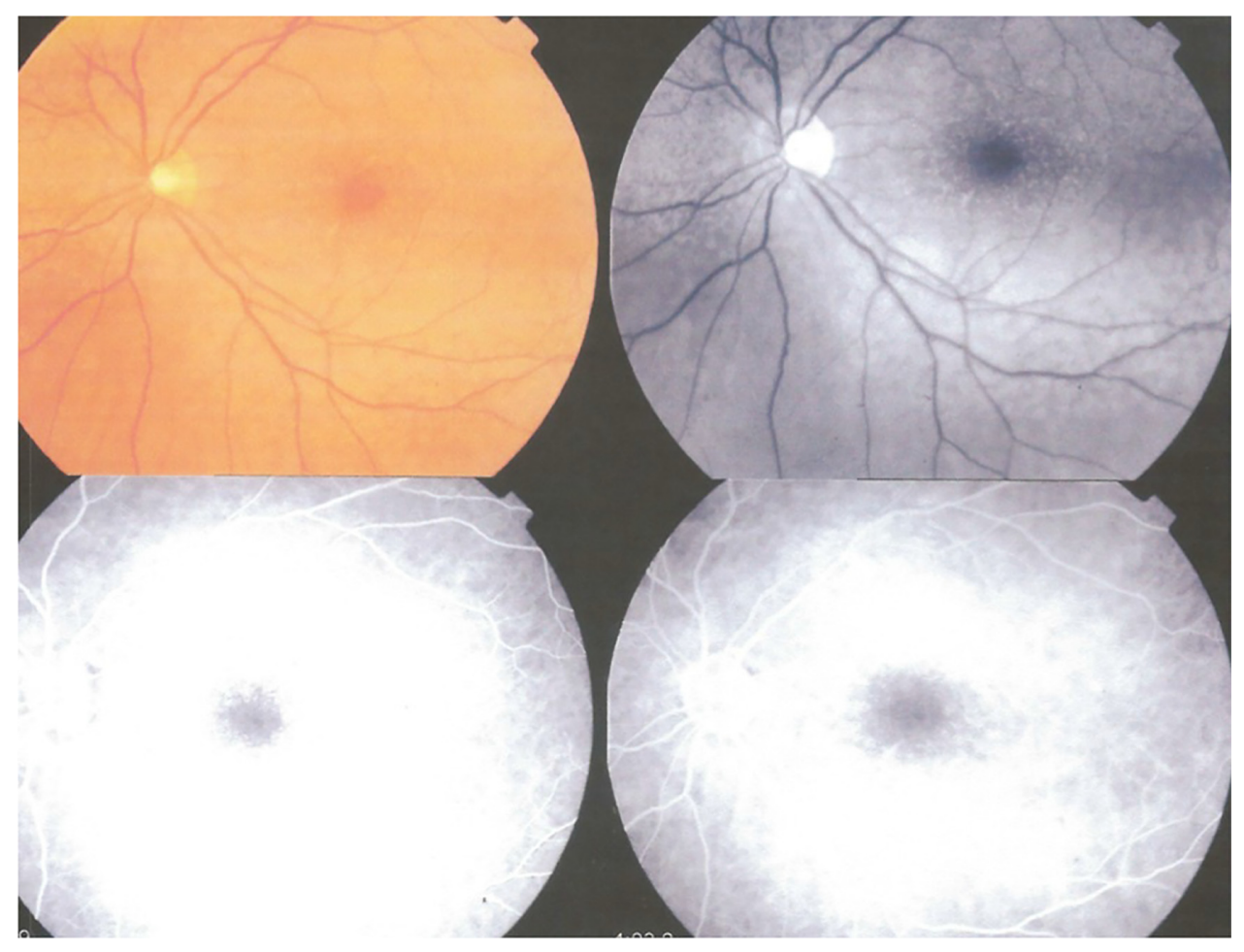

Figure 2 Initial fundus photographs of the left eye with fluorescein angiography transit show an unaffected macula (February 20I2). Note: Routine view of a fluorescein angiogram: color, red free, and two transits of dye. 

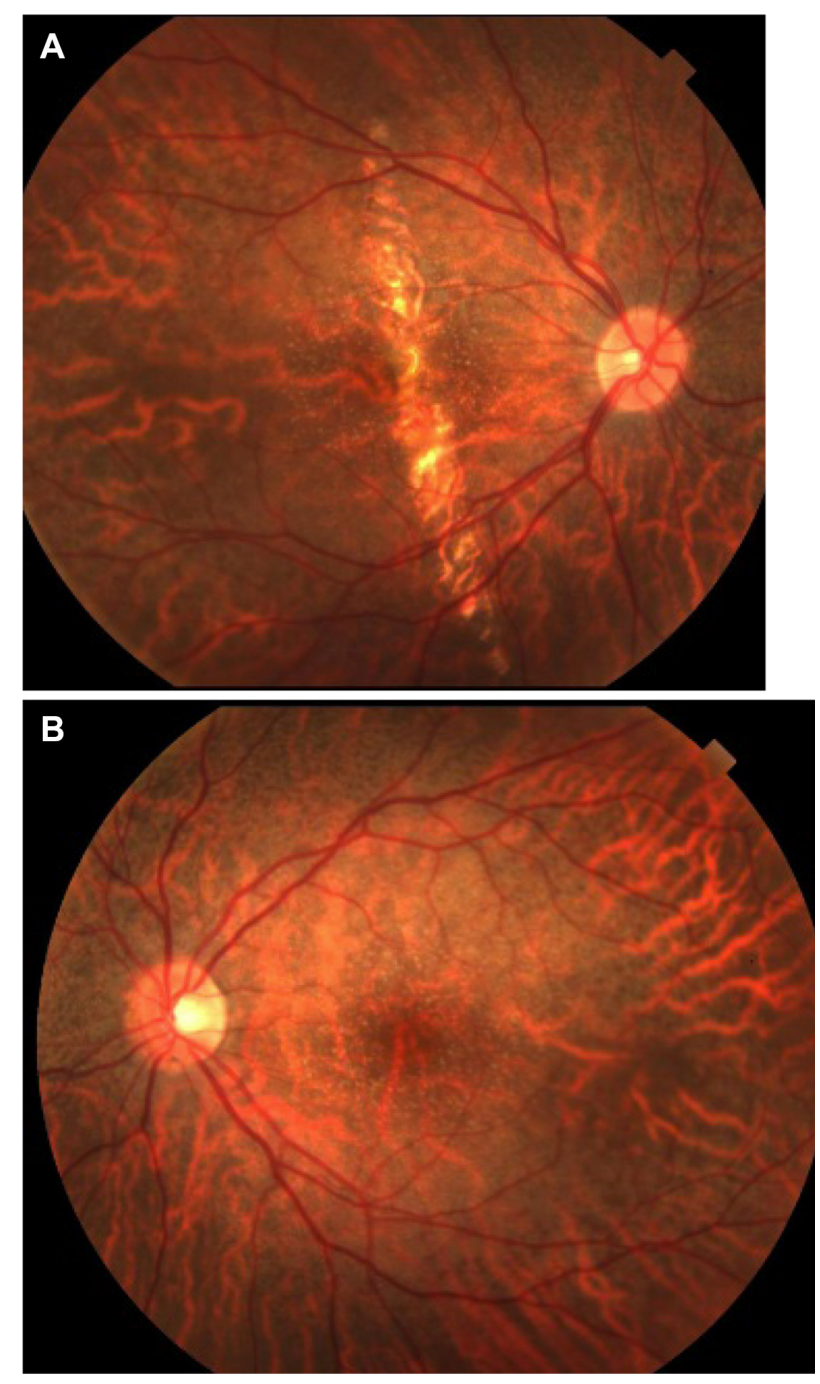

Figure 3 Fundus photographs taken 6 months after initial photographs. Notes: Images show more widening of the lacquer crack in the right eye (A) with no changes observed in the left fovea (B) (September 20I2). The right eye underwent three monthly intravitreal injections just after this photographic capture.

\section{Case report}

A 43-year-old married Syrian woman presented at the age of 40 with distortion of central vision in the right eye. Choroidal dystrophy was suspected in Damascus (Syria) (Figures 1 and 2). Rheumatology and infectious workup was negative (syphilis, tuberculosis, anti-double-stranded DNA, anti-single-stranded DNA, rheumatoid factor). CNV was also detected in the macular area in Dubai (United Arab Emirates) and intravitreal injections were advised. She subsequently received three monthly intravitreal ranibizumab injections in Barcelona (Spain) (Figure 3A and B). Past ocular history revealed myopia of $2.5 \mathrm{D}$ as per patient recollection. She had undergone bilateral refractive surgery (excimer laser 5 years ago followed by laser in situ keratomileusis [LASIK] 3 years ago). Medical history was negative. There was a strong family history of myopia and
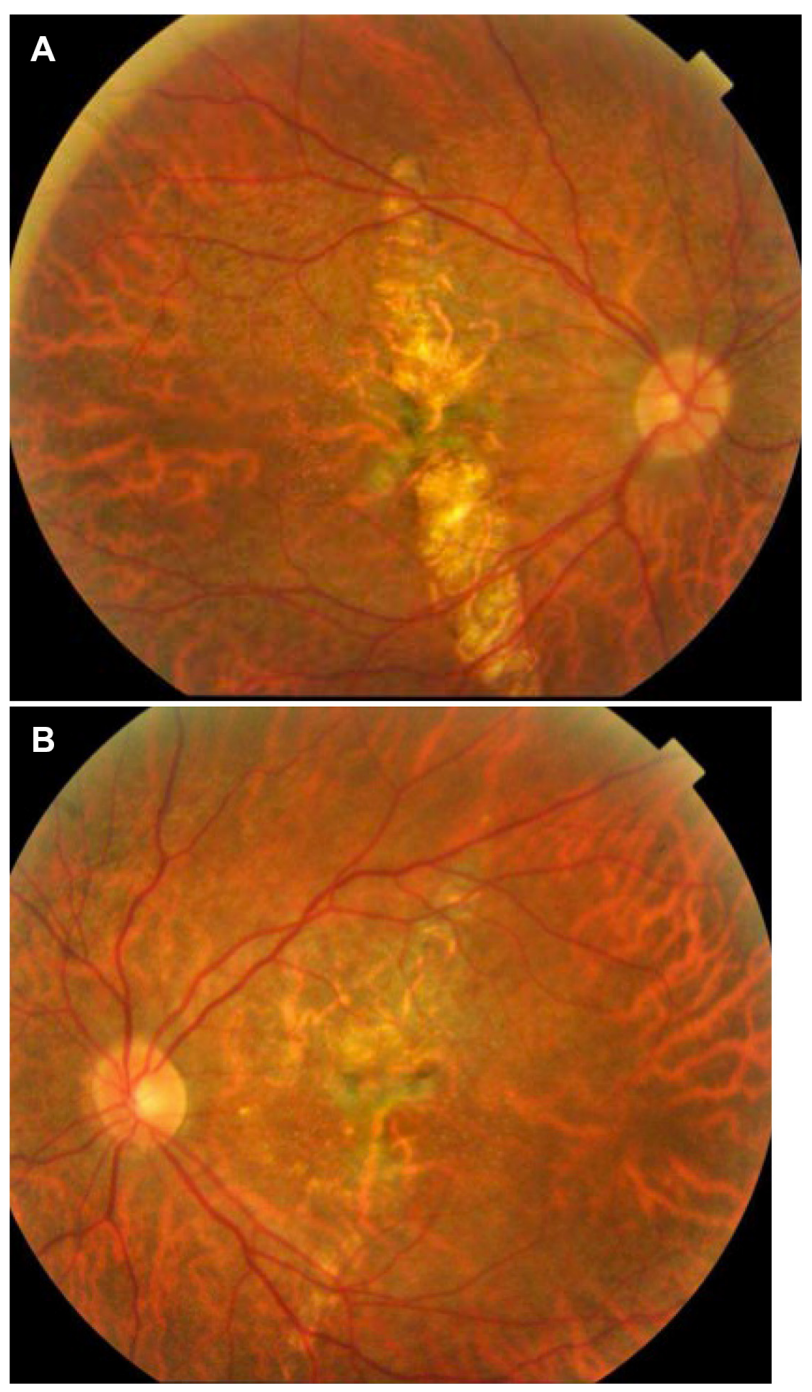

Figure 4 Fundus photographs of the right (A) and left (B) eyes 27 months after the first fundus examination.

Notes: There is further enlargement of the lacquer crack in both eyes (May 2014). Enlargement continued through until February 2015 (3 years after the initial photographs were taken).

no parental consanguinity. Fifteen months after initial right eye involvement, the patient expressed the same symptoms in the left eye, such as seeing broken lines and asymmetric faces. She was advised to undergo treatment for CNV in the macular region. She received one injection in Beirut (Lebanon), and subsequently, three monthly injections in Dubai to the left eye. She reported further worsening of vision after each injection. Consultation in London (UK) revealed a best-corrected visual acuity of 20/80 in the right eye and $20 / 30$ in the left eye. Dilated fundoscopy revealed bilateral areas of vertically linear atrophy, more extensive in the right eye, without subretinal fluid or hemorrhage by optical coherence tomography. Fundus autofluorescence imaging revealed areas of reduced autofluorescence corresponding to these areas of atrophy. The reported clinical impression 


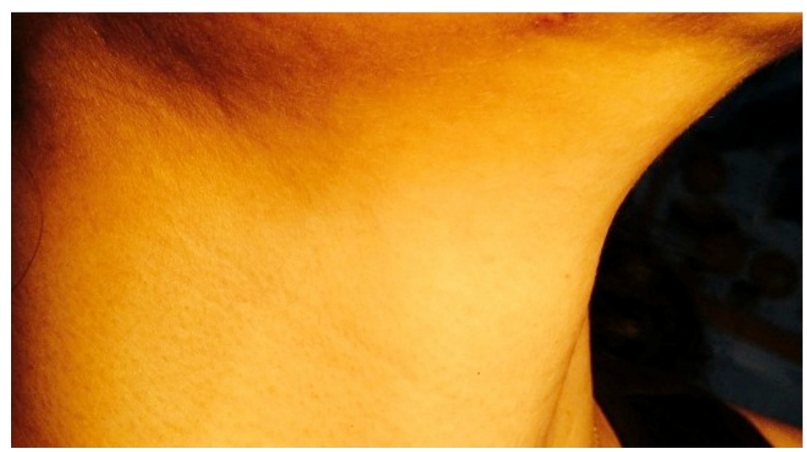

Figure 5 External appearance of the neck area revealed tiny pinkish papules.

then was myopic chorioretinal degeneration versus lacquer crack-associated myopic degeneration. She was advised to have regular checkup without intravitreal injections as long as the macula stays dry. The patient was frustrated because of both inability to pinpoint a definite diagnosis and gradual decline in vision bilaterally. Nine months later, she initially presented to our clinic with 20/200 visual acuity. Fundoscopy revealed definite widening of the vertical macular choroidal rupture bilaterally (Figure 4A and B). Stippled changes in the retinal pigment epithelium were observed. Peau d'orange appearance was not present. The patient was emmetropic without keratoconus on corneal topography. Axial length measurement with the IOL Master (Carl Zeiss Meditec AG, Jena, Germany) was $27.35 \mathrm{~mm}$ in the right eye and $27.31 \mathrm{~mm}$ in the left eye. Keratometry readings were $38.6 \mathrm{D}$ in the right eye and 38.2 D in the left eye. The skin of the neck had tiny pinkish papules suspicious for early goose flesh (Figure 5). Two separate dermatology consultations and skin biopsies did not favor the diagnosis of pseudoxanthoma elasticum. Even further widening of the choroidal rupture occurred 9 months after presentation. Our working diagnosis was lacquer crack from high myopia (without pseudoxanthoma elasticum) (Figure 6) possibly initiated by LASIK and exacerbated by ocular rubbing and intravitreal injections (Figure 7). The patient was instructed to avoid ocular rubbing,

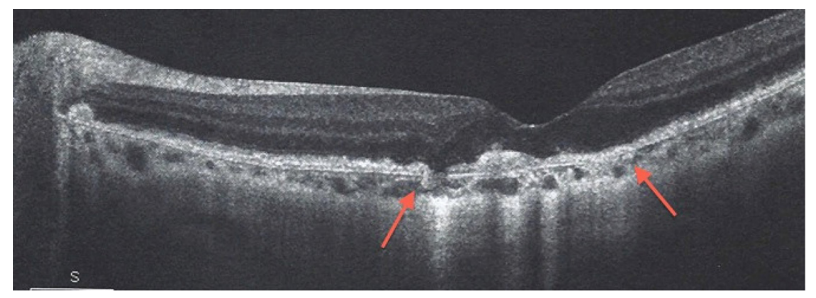

Figure 6 High-definition horizontal OCT scan of left optic disc and macula showing the sites of Bruch's membrane rupture (arrows).

Note: The fovea is attenuated with marked distortions in the inner segment/outer segment junction (October 20I4).

Abbreviation: OCT, optical coherence tomography.

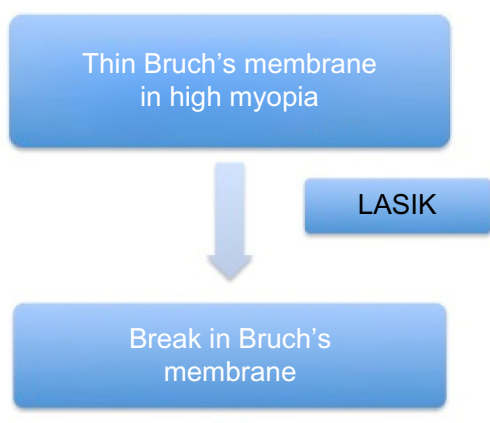

\section{Ocular rubbing}

Enlargement of the break

in Bruch's membrane

Intravitreal injections

Widening of choroidal rupture

Figure 7 Proposed pathophysiology of lacquer crack formation and expansion in the current case.

Abbreviation: LASIK, laser in situ keratomileusis.

head-down position, and intravitreal injection (unless an exudative component was present) and to have prior paracentesis before any future intravitreal injections.

\section{Discussion}

We propose the following pathophysiology to explain several findings in the present case (Figure 6). Macular lacquer cracks can occur spontaneously ${ }^{7,8}$ or just after LASIK procedures. ${ }^{9}$ In these high myopes that undergo LASIK, mechanical stress caused by intraocular pressure (IOP) elevation from the pneumatic suction ring may induce tangential stress at the posterior segment (sudden increase in IOP to $60-70 \mathrm{mmHg}$ ). ${ }^{7}$ Another potential cause of stress might be the impact of excimer laser on the cornea producing stress waves along the axis of the eye. Stress wave amplitudes during photoablation reach a maximal pressure focus of up to 100 atmospheres located in the posterior lens and anterior vitreous and then decrease to below 10 atmospheres at the retina. ${ }^{12}$ In addition, IOP increases by an average of $30 \mathrm{mmHg}$ in eyes without reflux, 1 minute after intravitreal injections. ${ }^{13}$ This acute IOP elevation puts stress on a weak, thin, and brittle Bruch's membrane leading to cracks. Via a similar mechanism, oculopression (ocular massage) can cause dehiscence of Bruch's membrane as reported by Ruderman et al, ${ }^{14}$ or 
as in our case, widening of the Bruch's membrane-choroid dehiscence. Rishi et al $^{15}$ described a 12 -year-old girl with osteogenesis imperfecta, with sudden visual loss in the left eye from choroidal neovascular membrane. She underwent treatment with intravitreal bevacizumab $(1.25 \mathrm{mg} / 0.05 \mathrm{~mL})$. Follow-up at 1 month revealed the development of lacquer crack running through the macula, underlying the fovea. The patient received two re-treatments at 1-month intervals with further progression of lacquer cracks, while CNV had regressed and vision stabilized at the 20/200 level. It is also conjectured that the further widening of the lacquer crack occurred as a result of transient increase in IOP following the intravitreal injection. There has been a similar event of enlargement of angioid streaks following intravitreal bevacizumab in an eye with $\mathrm{CNV}^{6}$ Also, choroidal ruptures were observed after intravitreal injection of bevacizumab for aggressive retinopathy of prematurity. ${ }^{3}$

\section{Conclusion}

We presented a case of extremely wide lacquer crack that resembled an angioid streak and led to some difficulty in diagnosis and management, especially with the absence of a history of high myopia. Many high myopes have progressive enlargement of the posterior sclera causing passive stretch on a brittle, thinned out Bruch's membrane. Hence, these eyes are at moderate risk for Bruch's membrane rupture and these breaks can enlarge with time. Care needs to be exerted in such eyes in order to avoid IOP rise from blunt ocular trauma, ocular rubbing, and ocular surgery such as LASIK, intravitreal injections, and phakic lens implant.

\section{Acknowledgment}

The institutional review board at Rafic Hariri University Hospital did not require the author to obtain ethics approval and patient consent because of the purely descriptive nature of an anonymous report.

\section{Disclosure}

The author reports no conflicts of interest in this work.

\section{References}

1. Aguilar JP, Green WR. Choroidal rupture. A histopathologic study of 47 cases. Retina. 1984;4(4):269-275.

2. Moon K, Kim KS, Kim YC. A case of expansion of traumatic choroidal rupture with delayed-developed outer retinal changes. Case Rep Ophthalmol. 2013;4(2):70-75.

3. Atchaneeyasakul LO, Trinavarat A. Choroidal ruptures after adjuvant intravitreal injection of bevacizumab for aggressive posterior retinopathy of prematurity. J Perinatol. 2010;30(7):497-499.

4. Mansour AM, Shields JA, Annesley WH Jr, el-Baba F, Tasman W, Tomer TL. Macular degeneration in angioid streaks. Ophthalmologica. 1988;197(1):36-41.

5. Mansour AM. Marked thickening of Bruch's membrane in a 17-year-old patient with angioid streaks. Eye (Lond). 1998;12(5):898-900.

6. Sen PR, Rishi P, Sen P, Rishi E, Shroff D. Rapid progression of angioid streaks following intravitreal bevacizumab. Can J Ophthalmol. 2009;44:e39-e40.

7. Ohno-Matsui $\mathrm{K}$, Tokoro $\mathrm{T}$. The progression of lacquer cracks in pathologic myopia. Retina. 1996;16(1):29-37.

8. Kim YM, Yoon JU, Koh HJ. The analysis of lacquer crack in the assessment of myopic choroidal neovascularization. Eye (Lond). 2011;25(7):937-946.

9. Ruiz-Moreno JM, Montero J, Alio JL. Lacquer crack formation after LASIK. Ophthalmology. 2003;110(8):1669-1671.

10. Chen S, Hodge C, Sutton G, Versace P, Anaes D. Lacquer cracks developing after phakic intraocular lens implantation. $J$ Refract Surg. 2014;30(9):646-648.

11. Hirata A, Negi A. Lacquer crack lesions in experimental chick myopia. Graefes Arch Clin Exp Ophthalmol. 1998;236(2):138-145.

12. Krueger RR, Seiler T, Gruchman T, Mrochen M, Berlin MS. Stress wave amplitudes during laser surgery of the cornea. Ophthalmology. 2001;108(6):1070-1074.

13. Kim JE, Mantravadi AV, Hur EY, Covert DJ. Short-term intraocular pressure changes immediately after intravitreal injections of anti-vascular endothelial growth factor agents. Am J Ophthalmol. 2008;146(6):930-934.

14. Ruderman JM, Jampol LM, Krueger DM. Visual loss caused by subretinal hemorrhage and rupture of Bruch's membrane after digital ocular massage. Am J Ophthalmol. 1988;106(4):493-494.

15. Rishi $P$, Rishi E, Venkatraman $A$. Intravitreal bevacizumab for treatment of choroidal neovascularization associated with osteogenesis imperfecta. Indian J Ophthalmol. 2012;60(3):229-231.
International Medical Case Reports Journal

\section{Publish your work in this journal}

The International Medical Case Reports Journal is an international, peer-reviewed open-access journal publishing original case reports from all medical specialties. Previously unpublished medical posters are also accepted relating to any area of clinical or preclinical science. Submissions should not normally exceed 2,000 words or

\section{Dovepress}

4 published pages including figures, diagrams and references. The manuscript management system is completely online and includes a very quick and fair peer-review system, which is all easy to use. Visit http://www.dovepress.com/testimonials.php to read real quotes from published authors. 